\title{
Message from the Incoming Editor-in-Chief
}

$\mathbf{I}^{1}$ T IS A GREAT HONOR for me to follow Dr. Krishnaswamy Nagaraj as the Editor-in-Chief of the IEEE JoURnAl OF SOLID-STATE CIRCUITS. Dr. Nagaraj has served the JOURNAL during the past three years in an outstanding way by attracting a very strong editorial board and keeping a huge database of manuscripts very well organized. The IEEE JOURNAL OF SOLID-STATE CIRCUITS is a publication with an outstanding reputation in our field, thanks to the great efforts of many authors, associate editors, and especially our highly qualified reviewers from all over the world. All these people act as volunteers and I want to express my gratitude to all of them, and I hope to be able to count on their hard work in the future.

Digital Object Identifier 10.1109/JSSC.2007.903671
Technically there are many challenges in our solid-state area, such as analog, RF and digital circuit techniques in technologies where the gate lengths are just a few tens of nanometers long. But also in the area of circuits using MEMS and power conversion techniques I expect many new innovations. I am looking forward to receiving high-quality manuscripts from all over the world and working with my respected associate editors to keep the level of the JOURNAL as high as it is now. Serving the JOURNAL is a great privilege and honor for me, and I thank the Solid-State Circuits Society and community for giving me this opportunity.

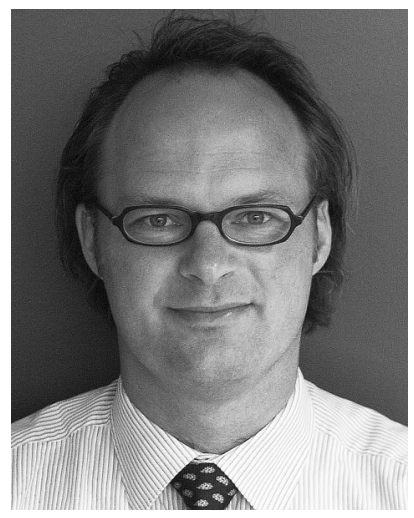

Bram Nauta (S'89-M'91-SM'03) was born in Hengelo, The Netherlands, in 1964. In 1987, he received the M.Sc degree (cum laude) in electrical engineering from the University of Twente, Enschede, The Netherlands. In 1991, he received the Ph.D. degree from the same university on the subject of analog CMOS filters for very high frequencies.

In 1991, he joined the Mixed-Signal Circuits and Systems Department of Philips Research, Eindhoven, The Netherlands, where he worked on high-speed A/D converters and analog key modules. In 1998, he returned to the University of Twente as full Professor heading the IC Design group, which is part of the CTIT Research Institute. His current research interest is high-speed analog CMOS circuits. He is also a part-time consultant in industry.

Prof. Nauta served as Associate Editor of the IEEE TRANSACTIONS ON CIRCUITS AND SYSTEMS PART II-ANAlOG AND Digital Signal PROCESSING (1997-1999), and as Guest Editor (1998) and Associate Editor (2001-2006) for the IEEE JOURNAL OF SOLID-STATE CIRCUITS. He is a member of the technical program committees of ISSCC, ESSCIRC, and the Symposium on VLSI Circuits. He was co-recipient of the ISSCC 2002 Van Vessem Outstanding Paper Award. 